University of Nebraska - Lincoln

DigitalCommons@University of Nebraska - Lincoln

USDA National Wildlife Research Center - Staff Publications
U.S. Department of Agriculture: Animal and Plant Health Inspection Service

April 1998

\title{
Anthraquinone protects rice seed from birds
}

Michael L. Avery

USDA/APHIS/WS National Wildlife Research Center, michael.I.avery@aphis.usda.gov

John S. Humphrey

John.S.Humphrey@aphis.usda.gov

Thomas M. Primus

U.S. Department of Agriculture, National Wildlife Research Center,

David G. Decker

U.S. Department of Agriculture, National Wildlife Research Center,

Arlene P. McGrane

U.S. Department of Agriculture, National Wildlife Research Center,

Follow this and additional works at: https://digitalcommons.unl.edu/icwdm_usdanwrc

Part of the Environmental Sciences Commons

Avery, Michael L.; Humphrey, John S.; Primus, Thomas M.; Decker, David G.; and McGrane, Arlene P., "Anthraquinone protects rice seed from birds" (1998). USDA National Wildlife Research Center - Staff Publications. 614.

https://digitalcommons.unl.edu/icwdm_usdanwrc/614

This Article is brought to you for free and open access by the U.S. Department of Agriculture: Animal and Plant Health Inspection Service at DigitalCommons@University of Nebraska - Lincoln. It has been accepted for inclusion in USDA National Wildlife Research Center - Staff Publications by an authorized administrator of DigitalCommons@University of Nebraska - Lincoln. 


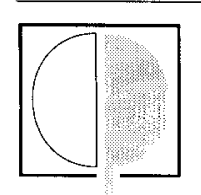

\title{
Anthraquinone protects rice seed from birds
}

\author{
Michael L. Avery*‡ John S. Humphrey* Thomas M. Primus ${ }^{\dagger}$ David G. Decker ${ }^{\star}$ and Arlene \\ P. McGrane* \\ *U.S. Department of Agriculture, National Wildlife Research Center, 2820 East University \\ Avenue, Gainesville, FL 32641-6033, USA and ${ }^{\dagger}$ U.S. Department of Agriculture, National \\ Wildlife Research Center, 3350 Eastbrook Drive, Ft. Collins, CO 80525, USA
}

\begin{abstract}
Application of bird-repellent chemicals to seed prior to planting is one possible approach to reducing bird damage to rice. Anthraquinone is a promising seed treatment compound, and in this paper we describe a sequence of tests evaluating a formulated commercial anthraquinone product. In 1-cup cage tests, rice consumption by individual male red-winged blackbirds (Agelaius phoeniceus) and female boat-tailed grackles (Quiscalus major) was reduced $64-93 \%$ by 0.5 and $1.0 \%(\mathrm{~g} / \mathrm{g})$ anthraquinone treatments. Daily rice consumption by single male boat-tailed grackles tested in large enclosures was reduced from $>14 \mathrm{~g}$ in pretreatment to $<1 \mathrm{~g}$ by a $1.0 \%$ treatment. One of five test birds atc nothing during a 1 day post-treatment session. In a 7 day trial within a 0.2 ha flight pen, a group of four male grackles consumed $1.3 \%$ of anthraquinone-treated rice seed compared to $84.1 \%$ of sorghum, a nonpreferred alternate food. At two study sites in southwestern I ouisiana, loss of rice sprouts in 2 ha plots sown with anthraquinone-treated seed was 0 and $12 \%$ compared to losses of $33 \%$ and $98 \%$ in nearby untreated plots. The formulation performed well at every stage of testing, and further development of anthraquinone products for bird-damage management is warranted. Published by Elsevier Science Ltd
\end{abstract}

Keywords: anthraquinone; Agelaius phoeniceus; bird repellent; Quiscalus major; rice; seed treatment; blackbird

Recent research has identified several compounds that have potential utility as nonlethal bird repellents (Mason, 1990; Clark et al., 1991; Avery and Decker, 1992; Watkins et al., 1995). With the notable exception of methyl anthranilate (Vogt, 1994), commercial development of chemical repellents has not kept pace with discovery, however, and the need for practical, effective bird deterrents persists.

Costs of meeting regulatory requirements and limited market potential are major constraints to the commercial development of bird-repellent chemicals (Mason and Clark, 1992). Furthermore, specific uses often require that the repellent formulation possess unique features. For example, to protect seeds from depredations by birds, the formulation should not bind the active ingredient too tightly to the seed. Granivorous birds remove as little as $15 \%$ of chemical seed treatments (Avery et al., 1997a), so if the repellent is bound too tightly, the bird will be minimally exposed to it. Conversely, repellents that are volatile will need to be encapsulated to prevent their dissipation and to prolong repellency (Avery et al., 1995).

To reduce bird damage to rice seed, the repellent formulation must remain viable after prolonged immersion because much seed is water-planted and even dry-sceded fields arc flooded soon after seeding.

${ }^{\ddagger}$ To whom correspondence should be addressed (Tel.: +352-375-2229; fax: +352-377-5559; e-mail: dwrc-ffs@afn.org).
Thus, low water solubility is desirable for a birddeterrent rice seed treatment. Furthermore, any seed treatment is unsuitable if it interferes with the normal germination and growth of the seed and seedling.

Few compounds satisfy each of these characteristics, have acceptably low cost and are environmentally benign. Methiocarb (4-[Methylthio]-3,5-xylyl methylcarbamate) possesses an array of desirable qualities and is a very effective bird repellent (Holler et al., 1982). However, there are concerns relating to aquatic toxicity, and the compound is not currently registered as a bird repellent (Dolbeer et al., 1994).

Anthraquinone, a naturally occurring chemical found in many species of plants (Thomson, 1987), also appears to meet the requirements for an effective bird repellent on rice seed. Anthraquinone was tested extensively as a seed treatment for forestry applications (Royall and Neff, 1961) and as a seed treatment on rice (Neff and Meanley, 1957) but was never registered as a bird repellent in the United States. In recent cage and pen trials, the repellency of technical grade anthraquinone to the most serious rice-depredating species was confirmed (Avery et al., 1997b). Here, we extend those findings to an anthraquinone formulation, $\mathrm{ABCO} \mathrm{AQ50}$ (ABCO Industries, Inc., Roebuck, S.C., USA; reference to trade names does not constitute endorsement of the product by the USDA) that contains $50 \%$ anthraquinone in aqueous suspension and is used as a pulping catalyst in the paper industry. Our objective was to 
quantify the repellent effect of the formulation against rice-depredating bird species in a sequence of feeding trials from simple cage tests to field evaluation. Bird damage to seeded rice is a persistent problem in the southern United States that costs producers millions of dollars annually (Wilson et al., 1989; Decker et al., 1990).

\section{Methods}

\section{General procedures}

Red-winged blackbirds (Agelaius phoeniceus) and boat-tailed grackles (Quiscalus major) were trapped near Gainesville, Florida and maintained in captivity for up to 4 months before testing. Birds were housed by species in $1.3 \times 1.3 \times 1.7 \mathrm{~m}$ cages in a roofed outdoor aviary with free access to quail starter feed (Hillandale Farms, Lake Butler, FL) and water. The mass of each bird was determined before and after testing, and each bird was banded and released.

Rice was bagged in $1 \mathrm{~kg}$ batches and soaked overnight. Wet bags were placed on the ground and covered with black plastic for 2 days to encourage germination. Then, each bag of soaked rice was placed in a rotating mixer with $20 \mathrm{ml}$ of AQ50, $1.2 \mathrm{ml}$ of a commercial adhesive (Latron CS-7, Rohm and Haas, Philadelphia, PA), and $10 \mathrm{ml}$ of water. Mixing continued for $5 \mathrm{~min}$, then the seed was air-dried and stored in an air-conditioned laboratory. Treatments are expressed in terms of the mass of active ingredient (anthraquinone) applied to the seed.

Germination of rice seed was evaluated by placing 10 seeds from each treatment level in $15 \mathrm{ml}$ of water within a covered Petri dish lined with filter paper. This was replicated three times for each treatment level. After 8 days, one-way ANOVA revealed no difference among treatments in the number of sprouted seeds ( $F=1.47 ; 2,6$ d.f.; $P=0.302)$.

\section{One-cup cage test}

The 1-cup feeding trial was conducted in a roofed outdoor aviary, where test cages $(45 \times 45 \times 45 \mathrm{~cm})$ were visually isolated and equipped with automatic waterers. Food was presented in clear plastic feed cups $(8.2 \mathrm{~cm}$ diameter, $3.8 \mathrm{~cm}$ high $)$ with a circular opening ( $3.1 \mathrm{~cm}$ diameter) in the top.

Four days before the start of the pretreatment period, birds were taken from their holding cages, weighed, and assigned to individual test cages. Test groups of six redwings were randomly assigned to 0 (Latron CS-7 only), 0.5 or $1.0 \%(\mathrm{~g} / \mathrm{g})$ anthraquinone treatments. Boat-tailed grackles were randomly assigned to receive either 0 or $1.0 \%$ treatments $\left(n=5\right.$ birds group $\left.{ }^{-1}\right)$. During a 4 day acclimation period, birds received a mixture of rice seed and quail starter.

Following acclimation, there was a 4 day pretreatment period and a 4 day treatment period. During pretreatment each food cup contained $30 \mathrm{~g}$ of soaked, untreated rice seed, and during the treatment phase birds received their assigned rice treatment. Daily during the treatment period, we video-taped one red-winged blackbird in the $1.0 \%$ treatment group to document immediate and subsequent behavioral responses to the anthraquinone treatment.

Throughout the study, maintenance food was removed at 08:00 h, and the test food cups offered $1 \mathrm{~h}$ later. Cups containing test food not exposed to birds were put in vacant cages to determine mass changes due to ambient moisture. After $3 \mathrm{~h}$, test food was removed and the birds' maintenance food provided. Contents of test food cups were weighed and consumption determined by subtraction after appropriate adjustments for spillage and moisture gain.

Aluminum trays suspended under each cage caught spillage which was used to estimate the proportion of seed removed from the cups that was actually eaten. Consumption was analyzed in a two-way repeated measures analysis of variance (ANOVA) with treatment level as the betweensubjects factor and day as the within-subjects factor (Steel and Torrie, 1980).

\section{One-bowl pen test}

Five male boat-tailed grackles were taken from holding cages and randomly assigned to individual outdoor test pens $(3.1 \times 9.1 \times 1.8 \mathrm{~m})$ equipped with shaded perches, a waterer and a feeding station. Test birds were visually isolated from each other. An observation blind was established next to one pen so that the bird's feeding activity and behavior could be documented.

During a 4 day acclimation period, each bird received a singlc bowl of quail startcr at the feeding station. Then for the next 4 days, the maintenance food was removed at 07:30 and replaced $1 \mathrm{~h}$ later with a bowl containing $50 \mathrm{~g}$ of soaked, untreated rice seed. The bowl was set on an aluminum pan to catch spillage. A separate bowl of rice was put in an unoccupied pen to determine mass change due to ambient moisture. The food bowls were removed after $3 \mathrm{~h}$ and maintenance food provided again. A 4 day treatment period followed during which procedures were the same as in pretreatment except that each bird received a bowl of rice treated with $1.0 \%$ anthraquinone. There was then a 1 day posttreatment period when all birds again received untreated rice. Paired $t$-tests (two-tailed) evaluated hypotheses that pretreatment rice consumption did not differ from that during the treatment and posttreatment periods.

\section{Flight pen test}

Within a 0.2 ha flight pen, we prepared a $6 \times 12 \mathrm{~m}$ plot and hand-broadcast $450 \mathrm{~g}$ of rice seed treated with $1.0 \%$ anthraquinone. An adjacent alternate plot was provisioned with $450 \mathrm{~g}$ of untreated sorghum seed. We selected sorghum as the alternate food because although grackles will eat sorghum, they do not prefer it (Avery et al., 1997a). Therefore, substantial consumption of sorghum would indicate that the treated rice seed was particularly unpalatable to the test birds. As soon as the plots were prepared, four male boat-tailed grackles were released into the flight 
pen where they were free to forage among the grass, weeds, bushes and small trees as well as on the seeded test plots. In each plot, we randomly located eight sampling quadrats $\left(0.2 \mathrm{~m}^{2}\right)$ and set the initial seed count in each to 48 , the average seed density for the test plot. The trial lasted for 7 days, and the number of seeds remaining on sampling quadrats was recorded daily at 11:00.

\section{Field test}

We selected two study sites in southwestern Louisiana, one in Allen Parish and one in Cameron Parish, where we established 2 ha treated plots and nearby 2 ha untreated plots. Each study site has a history of severe bird damage to seeded rice.

We seeded all plots at $112 \mathrm{~kg} / \mathrm{ha}$ with Lafitte foundation seed stock provided by the Louisiana State University (LSU) Rice Research Station, Crowley. Seed was treated without presoaking in $23 \mathrm{~kg}$ batches using a rotating seed treatment machine. To achieve a $1.0 \%$ anthraquinone treatment, we mixed $380 \mathrm{ml}$ of AQ50 in $1120 \mathrm{ml}$ of water and added this to the rotating seed. In addition, we added $2.4 \mathrm{ml}$ of Exhalt $800^{\circledR}$ (PBI-Gordon Corp., Kansas City, KS), a tank-mix encapsulator, to each batch of seed. Mixing continued for several minutes, until the seed flowed freely within the mixer.

Treated seed was stored in burlap bags until sown into flooded fields $4-5$ days later. Samples of treated and untreated seed were put into porous cloth bags that were placed in the flooded plots when the seed was flown on. The bags were retrieved 1, 3 and 5 days later for analysis of chemical remaining on the seeds. Study plots were drained 5 days after seeding, and bird activity was then documented until sprouts were counted. We recorded the numbers of birds in each plot at 5 min intervals for $1-2 \mathrm{~h}$ in the morning or in the late afternoon. Counts were made from a vehicle positioned to provide complete coverage of the plots yet not affect the activity of the birds.

Between 2 (Allen) and 3 weeks (Cameron) after seeding, sprout density was assessed by counting the number of rice sprouts in the sampling quadrats $\left(0.09 \mathrm{~m}^{2}\right)$ at 150 points randomly located throughout each plot. Sample points were distributed by randomly locating 30 transects across each plot, and then randomly assigning five sampling locations to each transect (Otis et al., 1983). In addition, at 10 random locations per plot, sprouts were counted in sampling quadrats protected from bird damage by wire exclosures. Counts from the exclosures served as a check to account for factors other than bird damage that might affect sprout density. At each study site, we compared mean sprout counts from transects in the treated plot with those in the untreated plot by applying onc-way ANOVA (Stcel and Torrie, 1980).

\section{Chemical analysis}

Rice from the field trial was first freeze-dried for $20 \mathrm{~h}$ at $-20^{\circ} \mathrm{C}$ and for $4 \mathrm{~h}$ at $-10^{\circ} \mathrm{C}$ to bring all samples to the same moisture content. Otherwise, water imbibed by rice in the flooded plots would bias the calculation of anthraquinone residues on the seeds. After being freeze-dried, samples were ground in a handheld coffee mill for $3 \mathrm{~min}$ to homogenize the samples. From each field sample, three subsamples of approximately $0.25 \mathrm{~g}$ were placed into glass test tubes, $25 \mathrm{ml}$ of methanol added to each tube and the tubes capped. Samples were then vortexed, shaken for $15 \mathrm{~min}$ and sonicated twice for $20 \mathrm{~min}$. Next, sample tubes were centrifuged for $5 \mathrm{~min}$ at approximately $2500 \mathrm{rpm}$ to separate the suspended solids of ground rice from the methanol extract. Aliquots of extract were transferred into vials, capped and anthraquinone concentrations determined by high performance liquid chromatography, Recovery efficiency was determined by analyzing samples of control rice that had been fortified with anthraquinone at $0.05,0.10$, 0.50 and $1.0 \%$.

\section{Results}

\section{Cage tests}

\section{Red-winged blackbird}

Whereas red-winged blackbirds exposed to untreated rice seed maintained consumption at pretreatment levels, anthraquinone treatments reduced $(F=24.07$; 2,15 d.f.; $P<0.001$ ) consumption during the 4 day test period (Figure 1). Mean consumption in the $0.5 \%$ group was slightly less than that of the $1.0 \%$ group because one bird given the higher rate ate more $\left(\bar{x}=4.70 \mathrm{~g} \mathrm{day}^{-1}, \mathrm{SE}=0.66\right)$ than the others. Among all test birds, consumption varied daily $(F=4.71 ; 3,45$ d.f.; $P=0.006$ ), being highest on day 1 $\left(\bar{x}=2.48 \mathrm{~g} \mathrm{bird}^{-1}, \mathrm{SE}=0.49\right)$ and least on day 3 $\left(\bar{x}=1.80 \mathrm{~g} \mathrm{bird}^{-1}, \mathrm{SE}=0.42\right)$. There was no interaction $(P=0.135)$ between treatment and day.

We video-taped two birds in the $1.0 \%$ treatment group. On the first day, bird 15 began by eating 44 rice seeds and then vomited 4 min later. In the next

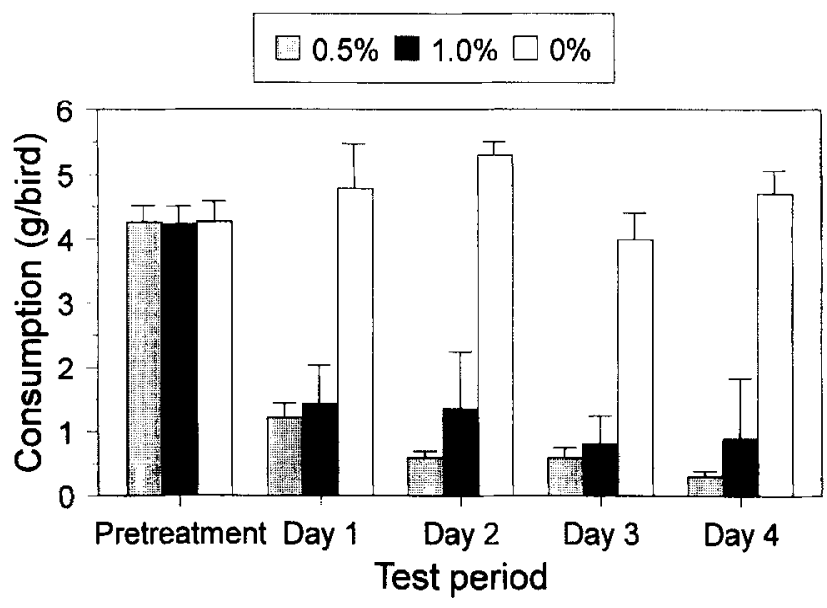

Figure 1. Mean rice consumption by groups of individually caged male red-winged blackbirds $\left(n=6\right.$ birds group ${ }^{-1}$ ) during daily $3 \mathrm{~h}$ feeding trials. During pretreatment, all seed was untreated. During the 4 day treatment period, seed was treated with anthraquinone at the rate indicated. Throughout the treatment period, consumption of seed by the 0.5 and $1.0 \%$ groups was reduced $(P<0.001)$ relative to that of the $0 \%$ group. Capped vertical lines denote 1 SE 
$9 \mathrm{~min}$, it ate nothing, made several visits to the water, and vomited five more times. It resumed feeding 16.5 minutes after it first vomited, and this time consumed 26 seeds. Bird 15 vomited 5.5 min later and twice more in the next $20 \mathrm{~min}$. It then resumed feeding, consumed 16 seeds, and vomited five times during the subsequent $23 \mathrm{~min}$. Shortly thereafter, it initiated another feeding bout and ate 17 seeds which resulted in two more vomits. During the remainder of the $2 \mathrm{~h}$ videotaping, the bird returned to the food cup several times without taking any seeds, and then, just before the end of the tape, it ate 15 during its fifth feeding bout. On day 2, the behavior of bird 15 started out the same; it ate 40 seeds during the initial feeding bout, and then vomited $7 \mathrm{~min}$ later. Thereafter, however, it took no more seeds despite revisiting the food cup several times. This bird ate $0.12 \mathrm{~g}$ on day 3 and $0 \mathrm{~g}$ on day 4 .

Bird 5 consumed $4.3 \mathrm{~g}$ of rice on day 1 and $5.9 \mathrm{~g}$ on day 2 , so we videotaped it on days 3 and 4 . This bird showed no evidence of discomfort or irritation and continued to consume rice at pretreatment levels. Unlike bird 15, bird 5 had short feeding bouts (usually three or four seeds) that were interspersed with periods of activity.

Mass loss by test birds did not differ among treatment groups $(P=0.105)$. Mean loss ranged from $1.0 \mathrm{~g}(\mathrm{SE}=0.5)$ in the control group to $2.9 \mathrm{~g}$ $(\mathrm{SE}=0.7)$ in the $1.0 \%$ group.

\section{Boat-tailed grackle}

Rice seed consumption was reduced markedly ( $F=10.14 ; 1,8$ d.f.; $P=0.013$ ) by the $1.0 \%$ treatment, and continued to decline throughout the 4 day treatment period (Figure 2). Consumption was highest $(F=16.26 ; \quad 3,24 \quad$ d.f.; $P<0.001)$ on day 1 $\left(\bar{x}=3.92 \mathrm{~g}\right.$ bird $\left.^{-1}, \mathrm{SE}=1.18\right)$ and least on day 4 $\left(\bar{x}=1.90 \mathrm{~g} \mathrm{bird}^{-1}, \mathrm{SE}=0.72\right)$. There was no carryover effect, however, as consumption returned to pretreatment levels when untreated seed was again offered (Figure 2). Body mass loss did not differ $(P=0.061)$ between the test groups.

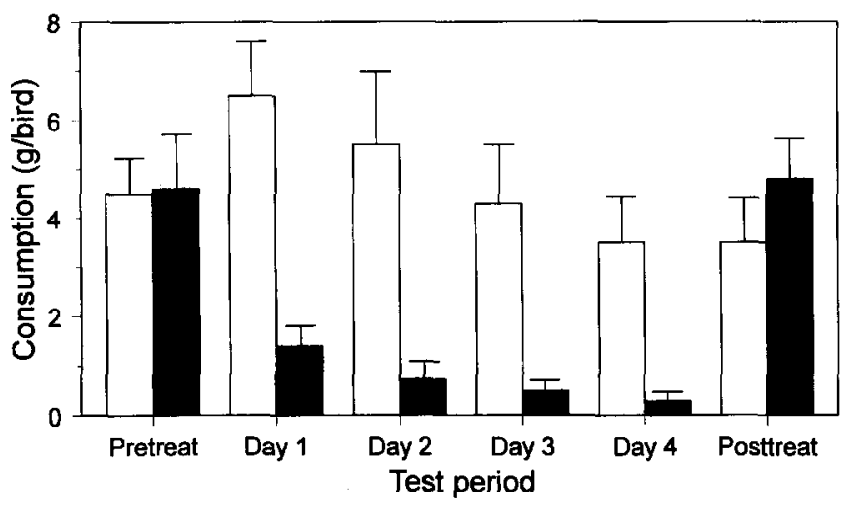

Figure 2. Mean rice consumption by groups of individually caged female boat-tailed grackles ( $n=5$ birds group ${ }^{-1}$ ) during daily $3 \mathrm{~h}$ feeding trials. During pretreatment and post-treatment, all seed was untreated. During the 4 day treatment period, one group received untreated seed (open bars) and the other group received rice that was treated with $1.0 \%$ anthraquinone. Consumption did not differ between groups during pretreatment and post-treatment, but was reduced $(P=0.013)$ by the anthraquinone treatment Capped vertical lines denote $1 \mathrm{SE}$

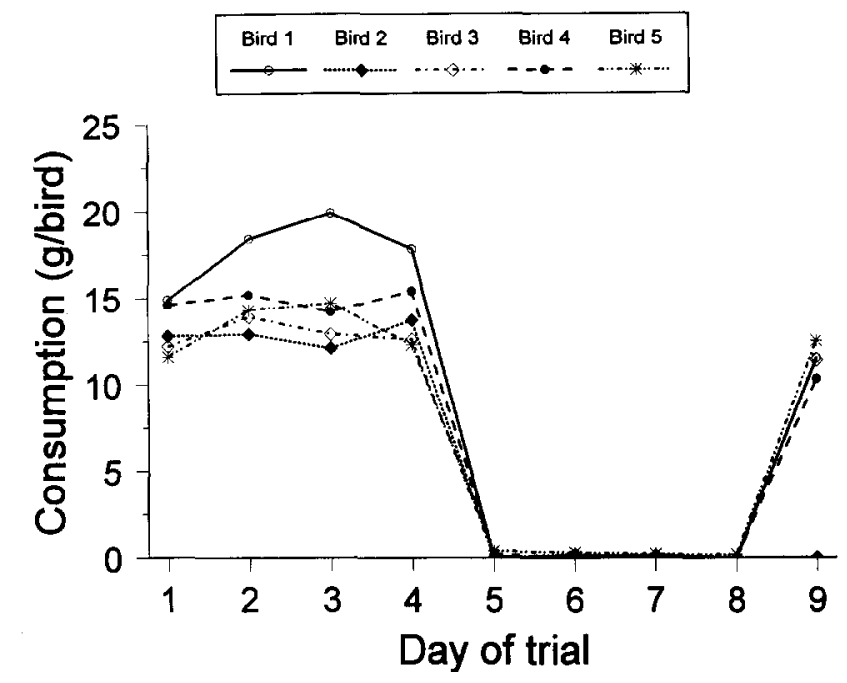

Figure 3. Rice consumption by five individually caged male boattailed grackles during daily $3 \mathrm{~h}$ feeding trials. During pretreatment (days 1-4) and post-treatment (day 9), all seed was untreated. During the treatment period (days $5-8$ ), birds received rice that was treated with $1.0 \%$ anthraquinone

\section{Enclosure test}

Consumption of rice seeds by male boat-tailed grackles was reduced $(t=15.00 ; 4$ d.f.; $P<0.001)$ to virtually zero by anthraquinone treatment at the $1.0 \%$ level (Figure 3). During 1 day post-treatment, when untreated rice was again provided, consumption returned to pretreatment levels $(t=2.36 ; 4$ d.f.; $P=0.077$ ), even though one bird refused to eat.

On treatment days $1-3$, bird 8 was at the food bowl within 70 s each day, and proceeded to take $2-7$ seeds within the first $5 \mathrm{~min}$. Thereafter, it made two or three additional visits to the food bowl during each $3 \mathrm{~h}$ trial and took no more than seven seeds during a single visit. On the post-treatment day, it arrived at the bowl within $30 \mathrm{~s}$ and ate 52 seeds in $7.5 \mathrm{~min}$. Throughout the trial, changes in body mass of test birds ranged from a loss of $5 \mathrm{~g}$ to a gain of $10 \mathrm{~g}$.

\section{Flight pen trial}

Throughout the 7 day trial, four male boat-tailed grackles removed five rice seeds (1.3\%) from sampling quadrats, compared to 323 sorghum seeds $(84.1 \%)$. Sorghum consumption increased markedly after day 3 (Figure 4).

\section{Field trial}

In Allen Parish, rice sprout density in the treated plot exceeded $(F=4.70 ; 1,58$ d.f.; $P=0.034)$ that in the untreated plot (Table 1). The treatment effect was even more marked at the Cameron site where sprouts in the untreated plot were exceedingly scarce $(F=1210.2 ; 1,58$ d.f.; $P<0.001)$.

Observations of bird activity at the study sites were consistent with the sprout count results. At the Allen Parish site, twice as many birds were observed per 5 min interval in the untreated plot $(\bar{x}=28$ birds count $\left.^{-1}, \mathrm{SE}=6\right)$ as in the plot treated with AQ50 $\left(\bar{x}=14\right.$ birds count $\left.^{-1}, \quad \mathrm{SE}=4\right)$. Red-winged blackbirds were predominant at the Allen Parish site, with 


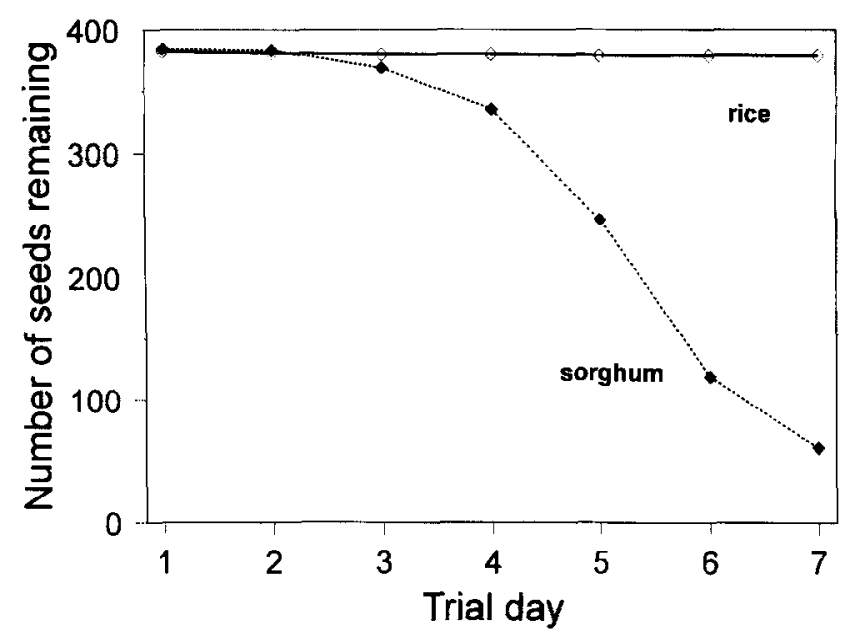

Figure 4. Number of rice and sorghum seeds removed from sampling quadrats by four male boat-tailed grackles during a 7 day trial within a 0.2 ha flight pen. Rice was treated with $1.0 \%$ anthraquinone and sorghum was untreated

brown-headed cowbirds (Molothrus ater) and common grackles (Quiscalus quiscula) also present. At the Cameron Parish site, where redwings and boat-tailed grackles were the most common species, birds were far more numerous in the untreated plot $\left(\bar{x}=16\right.$ birds count $\left.{ }^{-1}, \mathrm{SE}=6\right)$ than in the treated plot $\left(\tilde{x}=1\right.$ bird count $\left.^{-1}, \quad \mathrm{SE}=1\right)$. Blackbird and grackle activity there was consistently high in the untreated plot for 6 days after the water was drained, but then we seldom observed birds on either plot. The difference in bird activity between plots at the Cameron Parish site extended to species not normally associated with rice seed depredation. For example, during the 2 days immediately after draining, dozens of ibis (Plegadis spp.) foraged at the site, and they used the untreated plot almost exclusively.

Mean recovery of anthraquinone from fortified samples was $99.5 \%$. Analyses of treated seed showed initial anthraquinone levels of $0.740-0.752 \%$, approximately three-quarters of the intended treatment rate of $1.0 \%$. After $24 \mathrm{~h}$ in the field, anthraquinone residue on treated seed was approximately $0.606 \%$ and did not decline thereafter. No anthraquinone was detected on samples from the untreated plot.

\section{Discussion}

At every level of testing, from single birds in small cages to free-flying flocks in field trials, the AQ50 anthraquinone treatment very effectively protected rice seed from bird damage. Observations of one video-taped red-winged blackbird confirmed previous findings (Avery et al., 1997b) that anthraquinone repellency is accompanied by post-ingestional distress and vomiting. Interestingly, one anomalous bird avoided the adverse effects and continued to eat treated seed by restricting intake to a few seeds per bout. The apparent ability of birds to regulate feeding rate and avoid consumption of potentially lethal amounts of chemicals has been noted previously (Hill, 1972). The extent to which this occurs in the field is unknown but it could be a potential factor limiting the effectiveness of anthraquinone seed treatments.

At the Cameron Parish study site, our observation of ibis feeding extensively in the untreated plot while avoiding the treated plot raises the possibility that these birds were directly affected by the anthraquinone treatment applied to the rice seed. In early spring, ibis frequently forage in muddy, recently drained Louisiana rice fields (G. Wicke, pers. commun.). Although ibis have not been implicated in rice depredations, evidence from elsewhere shows that they do eat large quantities of rice in the nonbreeding season (Acosta et al., 1996). Our observations are consistent with this finding. The food habits of ibis in newly seeded rice fields warrants further study.

Despite the illness-producing nature of anthraquinone, there is no evidence of permanent injury or death from anthraquinone exposure. Captive test birds maintained body mass and all appeared healthy when feeding trials ended. Anthraquinone has low acute oral toxicity to mammals (mouse $\mathrm{LD}_{50}=$ $5000 \mathrm{mg} \mathrm{kg}^{-1}$; Thomson, 1988) and to birds (red-winged blackbird $\mathrm{LD}_{50}=100->300 \mathrm{mg} \mathrm{kg}^{-1}$; Schafer, 1972). Whereas dietary toxicity tests have not been performed on rice-depredating species, results of our flight pen and field trials indicate that when birds have alternatc food sources, they will not feed extensively on rice seed treated with anthraquinone. Thus, the likelihood of lethal dietary exposure is remote.

Generally, anthraquinone is inexpensive; current information suggests that the price of an anthraquinone-based rice seed treatment will be $<\$ 30 / \mathrm{ha}(\mathrm{K}$. E. Ballinger, Jr, EBI, Wilmington, DE, unpubl. data). This means that even when bird damage is not a certainty, rice can be treated as a prophylactic measure with relatively little expense. Even though

Table 1. Rice sprouts counted in 150 sampling quadrats $\left(0.09 \mathrm{~m}^{2}\right)$ throughout blackbird repellent test plots and under bird-proof exclosures $\left(n=10\right.$ plot $\left.^{-1}\right)$ within the test plots at two locations in southwestern Louisiana, March-April 1997

Sprout density (plants quadrat ' 1 )

\begin{tabular}{|c|c|c|c|c|c|c|c|c|}
\hline \multirow[b]{3}{*}{ Study site } & \multicolumn{4}{|c|}{ Test plots } & \multicolumn{4}{|c|}{ Exclosures } \\
\hline & \multicolumn{2}{|c|}{ Treated } & \multicolumn{2}{|c|}{ Control } & \multicolumn{2}{|c|}{ Treated } & \multicolumn{2}{|c|}{ Control } \\
\hline & $\bar{x}$ & SE & $\bar{x}$ & $\mathrm{SE}$ & $\bar{x}$ & $\mathrm{SE}$ & $\bar{x}$ & $\mathrm{SF}$ \\
\hline Allen & 19.5 & 2.1 & 14.6 & $1.0^{\mathrm{a}}$ & 22.1 & 6.2 & 21.7 & 3.3 \\
\hline Cameron & 12.4 & 0.4 & 0.1 & $0.1^{\mathrm{a}}$ & 10.2 & 3.2 & 5.9 & 1.9 \\
\hline
\end{tabular}

"Statistically significant difference $(P<0.05)$ between treated and control plots. 
some of the anthraquinone was lost during the first $24 \mathrm{~h}$ in a flooded field, the formulation withstood soaking for 5 days and stayed on the seed at levels that repelled depredating birds. Even greater efficacy will result when a proper formulation is developed for water-seeded rice. Prospects for registering an anthraquinone product as a bird repellent treatment for rice seed will largely depend on the extent to which private industry and rice producers can commit resources to meet regulatory data requirements.

\section{Acknowledgements}

Funding was provided by the USDA National Wildlife Research Center and the Louisiana State University Rice Research Station at Crowley. J. A. Musick, E. A. Wilson, G. Wicke, F. Mougeout, L. M. White and W. C. Faulk provided logistical support and technical assistance during the field study. We are particularly indebted to rice producers $\mathbf{M}$. Taylor and $H$. Unkel for their enthusiastic cooperation. Following procedures approved by the Animal Care and Use Committee of the USDA National Wildlife Research Center, K. L. Roca and C. C. McClester maintained the test birds in captivity.

\section{References}

Acosta, M., Mugica, L., Mancina, C. and Ruiz, X. (1996) Resource partitioning between glossy and white ibises in a rice field system in southcentral Cuba. Colonial Waterbirds 19, 65-72

Avery, M. L. and Decker, D. G. (1992) Repellency of cinnamic acid esters to captive red-winged blackbirds. $J$. Wildl. Manage. 56 , 800-805

Avery, M. L., Decker, D. G., Humphrey, J. S., Aronov, E., Linscombe, S. D. and Way, M. O. (1995) Methyl anthranilate as a rice seed treatment to deter birds. J. Wildl. Manage. 59, 50-56

Avery, M. L., Fischer, D. L. and Primus, T. M. (1997) Assessing the hazard to granivorous birds feeding on chemically treated seeds. Pestic. Sci. 49, 362-366

Avery, M. L., Humphrey, J. S. and Decker, D. G. (1997) Feeding deterrence of anthraquinone, anthracene, and anthrone to riceeating birds. J. Wildl. Manage. 61, 1359-1365

Clark, L., Shah, P. S. and Mason, J. R. (1991) Chemical repellency in birds: relationship between chemical structure and avoidance response. J. Exp. Zool. 260, 310-322
Decker, D. G., Avery, M. L. and Way, M. O. (1990) Reducing blackbird damage to newly planted rice with a nontoxic clay-based seed coating. Proc. Vertebr. Pest Conf. 14, 327-331

Dolbeer, R. A., Avery, M. L. and Tobin, M. E. (1994) Assessment of field hazards to birds from methiocarb applications to fruit crops. Pestic. Sci. 40, 147-161

Hill, E. F. (1972) Avoidance of lethal dietary concentrations of insecticide by house sparrows. J. Wildl. Manage. 36, 935-939

Holler, N. R., Naquin, H. P., Lefebvre, P. W., Otis, D. L. and Cunningham, D. J. (1982) Mesurol ${ }^{\circledR}$ for protecting sprouting rice from blackhird damage in I ouisiana. Wildl. Soc. Bull. 10, 165-170

Mason, J. R. (1990) Evaluation of d-pulegone as an avian repellent. $J$. Wildl. Manage. 54, 130-135

Mason, J. R. and Clark, L. (1992) Nonlethal repellents: the development of cost-effective, practical solutions to agricultural and industrial problems. Proc. Vertebr. Pest Conf. 15, 115-129

Neff, J. A. and Meanley, B. (1957) Research on bird repellents: hird repellent studies in the eastern Arkansas rice fields. Unpublished report. US Dep. Int., Wildl. Res. Lab., Denver, CO

Otis, D. L., Holler, N. R., Lefebvre, P. W. and Mott, D. F. (1983) Estimating bird damage to sprouting rice. In: Vertebrate Pest Control and Management Materials: Fourth Symposium, ASTM STP 817 , ed. D. E. Kaukeinen. American Society for Testing and Materials, Philadelphia, pp. 76-89

Royall, W. C. Jr and Neff, J. A. (1961) Bird repellents for pine seeds in the mid-southern states. Trans. North Am. Willl. Nat. Resour. Conf. 26, 234-238

Schafer, E. W. Jr (1972) The acute oral toxicity of 369 pesticidal, pharmaceutical and other chemicals to wild birds. Toxicol. Appl. Pharmacol. 21, 315-330

Steel, R. G. D. and Torrie, J. H. (1980) Principles and Procedures of Statistics, 2nd edn. McGraw-Hill Book Co., New York, 633 pp

Thonson, R. H. (1987) Nuturully Occurring Quinones. III. Recent Advances. Chapman and Hall, London, $732 \mathrm{pp}$

Thomson, W. T. (1988) Agricultural Chemicals, Book III Fumigants, Growth Regulators, Repellents, and Rodenticides. Thomson Publishing, Fresno, CA, $210 \mathrm{pp}$

Vogt, P. F. (1994) ReJeX-iT 'M AG-36 as bird aversion agent for turf and agriculture. Proc. Vertebr. Pest Conf. 16, 275-278

Watkins, R. W., Gill, E. L. and Bishop, J. D. (1995) Evaluation of cinnamamide as an avian repellent: determination of a doseresponse curve. Pestic. Sci. 44, 335-340

Wilson, E. A., LeBoeuf, E. A., Weaver, K. M. and LeBlanc, D. J. (1989) Delayed seeding for reducing blackbird damage to sprouting rice in southwestern Louisiana. Wildl. Soc. Bull. 17, $165-171$

Received 28 July 1997

Revised 5 December 1997

Accepted 7 December 1997 